\title{
The recharge method of landfill leachate treatment
}

\author{
Yu Tian ${ }^{1,}$, Wenwei Zhang ${ }^{2, b^{*}}$, Jianhua Tang ${ }^{2}$ and Wen $\mathrm{Li}^{2}$ \\ 'Wuhan Environment Investment and Development Group Co., LTD \\ ${ }^{2}$ Wuhan Environmental Sanitation Science Research Institute

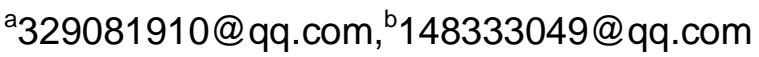

Keywords: recharge method, landfill leachate, COD removal rate, BOD removal rate

Abstract. With the continuous improvement of living standard and the acceleration of urbanization process, the output of city rubbish in unceasing increase year by year and the city rubbish is growing at an annual rate of $9 \% \sim 10 \%$.Relative to the method of incineration and compost treatment, sanitary landfill is the most commonly used methods in garbage disposal in China. However, plenty of leachate will produce in the process of landfill disposal, it may cause secondary pollution if not disposed well. Therefore, waste leachate treatment is critical to meet the requirement of environment. Due to the high concentration of pollutants in waste leachate, composition is complex and contains a large number of poisonous and harmful material, regular physical chemical method and biological treatment methods of waste leachate is very difficult to up to standard.

\section{Introduction}

The article researches the recharge method of landfill leachate treatment. The leachate recharge method is recharging leachate without any pretreatment, using the layers of soil to purify the soil. Leachate recharge treatment has the advantages of low investment, simple operation, low operating cost From 1990s began to study recharge method in China. The processing technology and research actualities of leachate recharge treatment have great practical significance and theory significance in the future.

In the early 1970s, American Pohland (1980) study found that the leachate recharge to the landfill site after a period of time, the pollutant concentration compared with leachate without treatment has been greatly reduced. DiminXu (1995) consider that after leachate recharge to landfill layer the organic pollutants in the leachate can be used by plentyof microbes, organic pollutants content in the landfill leachate reduce at the same time of microorganisms multiply. Landfill cover is equivalent to biological filter bed, under the action of the biological filter bed the VFA (volatile fatty acid), CODcr, BOD5 and TOC concentrations decrease rapidly (Qi Wang, etc., 2000).After reflow processing, theremoval rate of leachate in CODcr up to 95\%. The concentration of NH3 - N can be reduced to $10 \mathrm{mg} / \mathrm{L}$, in the condition of half aerobic at the same time, the concentration of organic matter in landfill leachate greatly reduced. The humidity of landfill increased when leachate recharged, and the microbial activity will also increase accordingly. Leachate recharge will significantly increase the humidity of garbage landfill site, so as to accelerate the aerobic microbial degradation, quicken the degradation rate of organic matter (Miller \& W L Townsend, T, in the summer of 1994,Yueqing Xia, 1999).Leachate recharge can accelerate the sedimentation rate of landfill site, and can make the total landfill subsiding extent increases, so as to improve the efficiency of the use of landfill. 
After landfill sealing, a large number of poisonous and harmful leachate produces in the long stabilization process, and release of flammable gas, at the same time uneven settlement occurred. Therefore landfill should be maintained after it closure, the leachate and landfill gas monitoring and process at regular intervals, until it is no longer brings pollution to the surrounding environment. The maintenance period of landfill that without reflux is 20 years or even hundreds of years commonly (Belevi H \&Baccini P, 1989), but for reflux landfill of the maintenance period is greatly shortened. It mainly because of the capacity of leachate can greatly reduce or even without processing. The method of landfill leachate can not only save the maintenance cost, but also reduce requirements of the lining of the anti-seepage performance.It is estimated that the maintenance cost of reflux landfill was only $45 \%$ of landfill leachate on-site treatment (Pohland F G \&Yousfi A, B, 1994).

Leachate recycling treatment mainly divided into three kinds: During the period of the landfill leachate directly back to junk; surface irrigation and irrigation to landfill surface; under the surface or the inner reflux. Leachate recharge during the landfill is a method of pouring into the leachate directly in the garbage dump into the landfill site compaction period. Surface irrigation is the use of evaporation principle to reduce the concentration of organic pollutants. The surface spraying and blind channel infiltration are two common surface reflux methods.

Although leachate recharge processing has many advantages, three issues are still unresolved. (1) The stench gas: Reflux will accelerate the volatilization of odorous gases, which led to the decrease of the quality of the atmospheric environment around. (2) The reflux technology cannot ensure sewage reached standard (GB 16889-1997)). The leachate circulating in the litter layer the NH4 + -n concentration is much higher than in others(KONX k. 1985). (3) The security problems caused by the speed up of production rate of the landfill gas (Yingjie sun, 2002).

Experimental research on recharge landfill leachate treatment technology. The method of leachate recharging is leachate cycle back onto the landfill layer without any pretreatment and controlling the parameters such as frequency, hydraulic load and organic load. Theprocess flows of recharge landfill leachate are shown in figure 1.

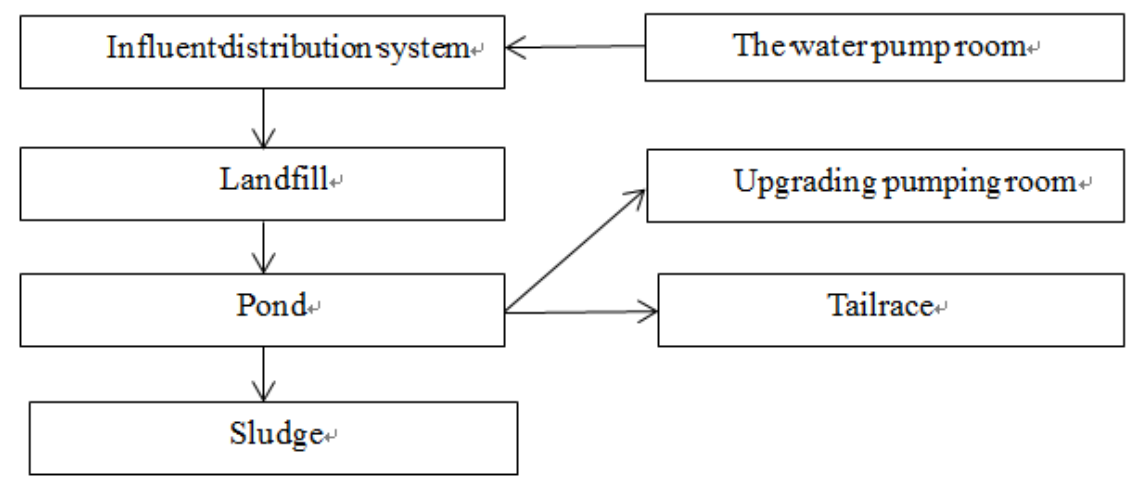

Figure 1 The process flows of recharge landfill leachate

In order to study the actual processing effect of leachate recharge method, a serious of theoretical research and calculation must be carried out. The landfill leachate recharge processing is based on the landfill cover soil purification effect and the degradation of landfill layers. This research recharge leachate to landfill layers using soil physical adsorption and microbial degradation of landfill layer to purify the leachate. Obviously, this method has the advantages of low investment, simple operation, good processing effect, and can overcome heavy metal pollution diffusion.

Test apparatus. Test apparatus using a simulated soil column andthe landfill column is a cylinder device with diameter $20 \mathrm{~cm}$. A perforated plate is at the bottom of the device, and leachate is 
addedon the top.The water flows from the bottom of the containerafter treatment, collectsand analysis the water daily. The test apparatusare shown in figure 2.

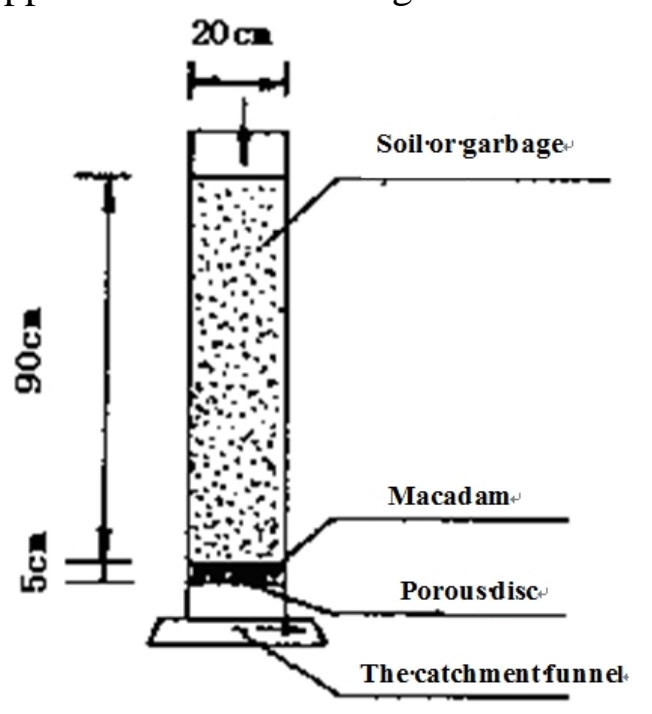

Figure 2 The diagram of test apparatus

Test materials. Test materials is silt with a certain amount of sand from Wuhan, and the silt :sand $=$ 6:1 (weight ratio).

The pile layer of landfills is constituted by litter layer and soil layer. The landfill leachate recharge treatment must make whole heap landfill layer can keep certain water permeability and air permeability, providing suitable living conditions of microorganisms. If pile layer porosity is too small, not only affect the growth of microorganisms but also cause poor permeability in the pile layer, so as to affect the operation of the whole system. For this reason, this paper will take the silt and sand as the object, to study purification effect and the influence of microorganisms.

This research adopts the mode of spraying leachate regularly intermittent, collecting and measuring concentration and volume of leachate in and out of the water on time every day $(\mathrm{P}=\mathrm{mg}$. $\left.\mathrm{L}^{-1}\right)$, and water volume $(\mathrm{V}=\mathrm{mL})$. To eliminate the evaporation in the experimental process, the volume dose of leachate COD, BOD is adopted in the study.

The test results. The microbe species and quantity in landfill layer and soil of has important influences on the degradation process of landfill leachate. At the beginning of the test, processing efficiency is not ideal for less biomass, after a period of time, with the appropriate biological establishment the treatment effect improved rapidly. It is shown infigure 3 that, at the beginning of the test the leachate COD removal rate was only 28\%, after 30 days or so leachate COD removal rate can be maintained at more than $98 \%$. This suggests that treatment effect is inseparable with biological functions.

After the leachate added into the experiment column 30 days, the ability of soil processing leachate was limited. Gradually increase theload of leachate in the process of test, the COD, BOD removal rate is shown in figure 3 to figure5. When leachate flow increases, COD, BOD removal rate began to fall. 


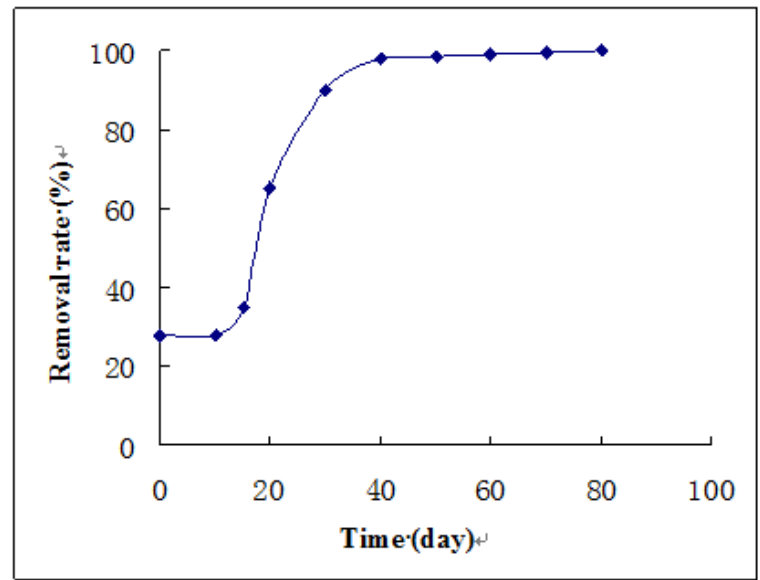

Figure 3 Leachate BOD、COD removal rate changes with time

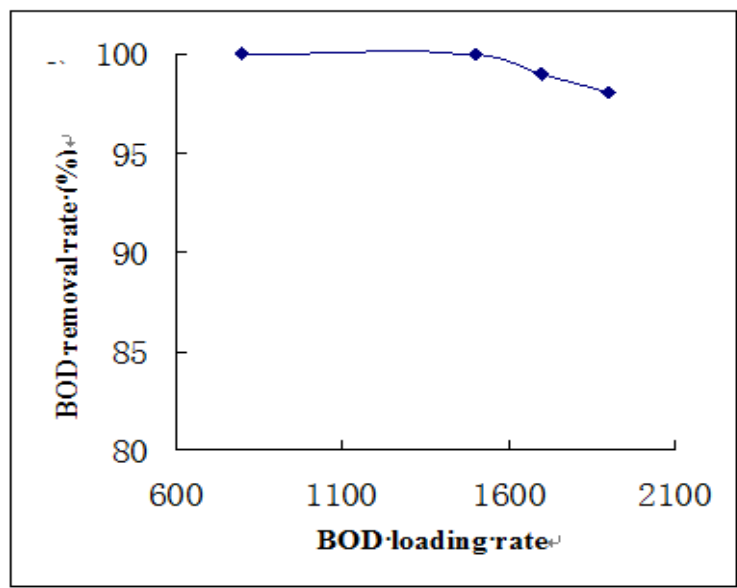

Figure 4 Leachate BOD removal rate changes with time

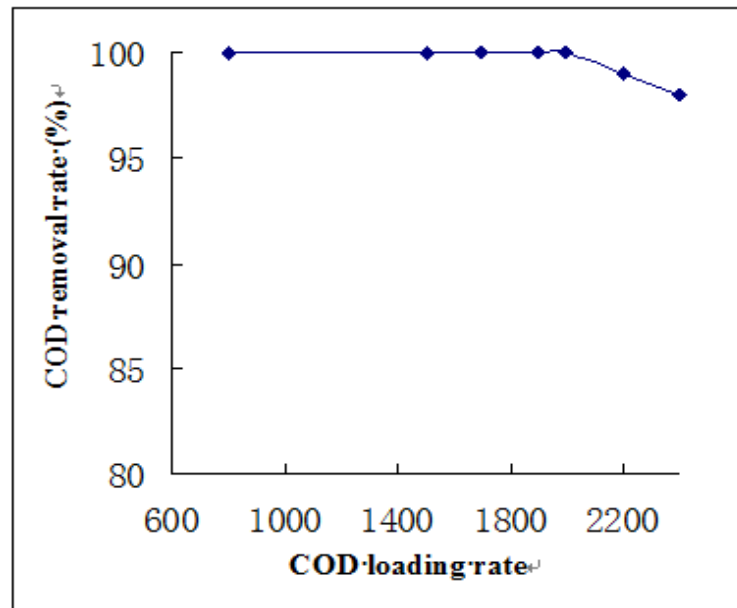

Figure 5 Leachate COD removal rate changes with time 


\section{Conclusion.}

The above experimental results show that the test soil column has significant effect on eliminate the $\mathrm{COD}$ and BOD in leachate. At the beginning of the experiment, the COD removal rate is low and increase gradually with time, after 30 days experiment the removal rate of COD can be up to $98 \%$. It shows that it needs certain time for soil layer of landfill to process leachate, at the same time it needs certain time for microorganisms growing. When the rate of leachate injected in soil column faster than the rate of microbial purification, the removal rate of COD in the soil column of leachate will significantly decline.

\section{References}

[1] Xiangdong Li, Ting Zhang, QiyanFeng and Hong Yang. COMPARISON OF LEACHATE CHARACTERIZATION IN

[2] ANAEROBIC-AEROBIC AND ANAEROBIC LANDFILL REACTORS, Fresenius Environmental Bulletin, Volume 21 - No 8. 2012,2003-2009. 